\title{
Función del ácido lisofosfatídico como regulador lipídico modulador del comportamiento
}

\section{Role of lysophosphatidic acid as lipid mediator in behavior}

\author{
Guillermo Estivill-Torrús ${ }^{1}$, Luis Javier Santín ${ }^{2}$, Carmen Pedraza ${ }^{2}$, Estela Castilla-Ortega ${ }^{2}$, \\ Fernando Rodríguez de Fonseca ${ }^{3}$ \\ ${ }^{1}$ Unidad de Microscopía, Fundación IMABIS, Málaga, España. ${ }^{2}$ Departamento de Psicobiología y Metodología de las Ciencias \\ del Comportamiento, Facultad de Psicología, Universidad de Málaga, España. ${ }^{3}$ Laboratorio de Medicina Regenerativa, Fundación \\ IMABIS, Málaga, España.
}

Disponible online 31 de diciembre de 2011

\begin{abstract}
El ácido lisofosfatídico (LPA, del inglés lysophosphatidic acid) es un fosfolípido endógeno implicado en numerosos y diferentes procesos celulares a través de receptores acoplados a proteína $\mathrm{G}$ específicos $\left(\mathrm{LPA}_{1-6}\right)$. El descubrimiento de una vía de señalización mediada por LPA en el cerebro en desarrollo y en el adulto permitió la caracterización posterior de sus funciones neurales. Los estudios realizados hasta la fecha por medio de aproximaciones experimentales tales como la deleción génica, que permitiera el desarrollo de animales nulos carentes de los receptores específicos, han representado una herramienta de indudable valía para demostrar la necesidad de, al menos, la expresión del receptor LPA para el desarrollo normal de la función cerebral y su función en numerosos procesos que incluyen la proliferación y diferenciación neural, supervivencia celular, sinapsis, neurotransmisión, o el balance neuroquímico, en diferentes áreas cerebrales y, de manera notable, en el hipocampo. Actualmente, son ya numerosos los trabajos que muestran alteraciones que afectarían a los procesos cognitivos y emocionales en correlación con las alteraciones estructurales y neuroquímicas descritas. En este artículo se revisan las funciones del LPA en el comportamiento particularizadas, principalmente, al receptor LPA, y se mencionan, igualmente, sus implicaciones en patologías psiquiátricas.
\end{abstract}

Palabras clave: Ácido lisofosfatídico; Comportamiento; Aprendizaje; Memoria; Esquizofrenia.

Lysophosphatidic acid (LPA) is an endogenous phospholipid which is involved in many different cellular processes through specific G-protein coupled receptors $\left(\mathrm{LPA}_{1-6}\right)$. The finding of a lysophosphatidic acid (LPA) signaling pathway in the developing and adult brain led to the characterization of the functional roles of LPA in normal and diseased brain. Previous studies using pharmacological or genetic approaches such as receptor null mice have been demonstrated as indispensable to determine the requirement of, at least, LPA 1 receptor for normal brain function and its influence in many different processes including neural cell proliferation and differentiation, cell survival, synapsis, neural transmission, or neurochemical balance in a variety of cerebral areas although, remarkably, the hippocampus. To date numerous contributions have showed behavioral alterations affecting cognition and emotional behavior in correlation with structural and neurochemical observations. Here we review the functions of LPA in behavior, principally particularized to those mediated by LPA receptor, and also discuss their relevance to psychiatric disorders

Keywords: Lysophosphatidic Acid; Behavior; Learning and Memory; Schizophrenia.

Correspondencia: Dr. Guillermo Estivill-Torrús. Unidad de Microscopía. Fundación IMABIS. Hospital Materno-Infantil. Planta Baja (junto a Hematología). Avenida Arroyo de los Ángeles s/n, 29009 Málaga. E-mail: guillermo.estivill@fundacionimabis.org. Correo electrónico de los autores: Luis Javier Santín: luis@uma.es, Carmen Pedraza: mdpedraza@uma.es, Estela Castilla-Ortega: ecastilla@uma.es, Fernando Rodríguez de Fonseca: fernando.rodriguez@fundacionimabis.org.

Queremos expresar nuestro más sincero agradecimiento a cada investigador del área, cuyo trabajo ha supuesto una indudable e importante contribución al campo, a la vez que manifestamos nuestra disculpa por las omisiones, no intencionadas. También agradecemos al Dr. Jerold Chun su apoyo y colaboración continuos. Este trabajo se ha realizado bajo la financiación del Programa I3SNS (GET), proyectos PI10/02514 (GET), SEJ-4515 (LJS), PSI2010-16160 (LJS), Red de Trastornos Adictivos RTA (RD06/001) (FRDF), CTS643 and CTS433 (Instituto de Salud Carlos III, Ministerios de Sanidad y de Ciencia e Innovación, Consejerías de Salud y de Innovación, Ciencia y Empresa, de la Junta de Andalucía), así como cofinanciado por el Fondo Europeo de Desarrollo Regional.

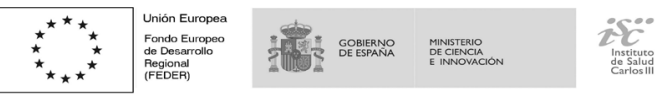


Los procesos que regulan el desarrollo del sistema nervioso central (SNC) precisan de una cuidadosa y bien orquestada secuencia de eventos que resulta imprescindible para la correcta funcionalidad cerebral. Las células progenitoras neurales, desde la zona ventricular, se expanden por medio de oleadas de progenitores que generarán los diferentes tipos celulares, neuronas, astrocitos y oligodendrocitos, y cuya migración actúa, a su vez, en coordinación con los procesos proliferativos así como de muerte celular programada, a objeto de realizar de manera equilibrada la génesis neural. Todos estos procesos se encuentran bajo la influencia de diferentes factores intrínsecos y señales extracelulares como, por ejemplo, los factores de crecimiento, que afectan a la morfología, división, destino o supervivencia celulares. De entre estos factores, los lisofosfolípidos y, especialmente, el ácido lisofosfatídico, han demostrado ser una influencia muy importante para el desarrollo del sistema nervioso.

El ácido lisofosfatídico (LPA, del inglés lysophosphatidic acid) es un fosfolípido simple endógeno bioactivo, constituyente relevante del suero, y liberado, bajo diferentes condiciones, en células y fluidos biológicos (Aoki, Inoue y Okudaira, 2008; Aoki et al., 2004; Van Meeteren y Moolenaar 2007). El LPA tiene importantes funciones biológicas actuando, como mediador intercelular y a través de, al menos, seis receptores específicos acoplados a proteína $\mathrm{G}$ de amplia distribución $\left(\mathrm{LPA}_{1-6}\right)$ en numerosos procesos celulares que incluyen proliferación, diferenciación, supervivencia y migración celular (Anliker y Chun, 2004; Birgbauer y Chun, 2006; Choi et al., 2010; Chun, 2007; Chun et al., 2010; Ishii, Fukushima, Ye y Chun, 2004; Moolenar, van Meeteren y Giepmans, 2004; Noguchi, Herr, Mutoh y Chun, 2009; Rivera y Chun, 2008). La demostración de una vía de señalización mediada por LPA en el sistema nervioso central sentó las bases para la posterior caracterización de las funciones del LPA en el cerebro hasta constituirse, a día de hoy, como una importante molécula reguladora en el cerebro normal así como bajo condiciones patológicas (Choi et al., 2010; Chun, 2005; Goldshmit, Munro, Yuen Leong, Pébay y Turnley, 2010; Lin, Herr y Chun, 2010; Noguchi et al., 2009). Un gran número de estudios han demostrado su participación, principalmente a través del receptor $\mathrm{LPA}_{1}$, en progenitores neurales o células troncales, neuronas, astrocitos, o en oligodendrocitos (Choi et al., 2008, 2010; Chun et al., 2000; Chun, 2005; Fukushima, Ye y Chun, 2004; Noguchi et al., 2009). Los diferentes efectos morfológicos y funcionales dependientes de la señalización mediada a través del receptor $\mathrm{LPA}_{1}$, así como la expresión específica de dicho receptor en las regiones neurogénicas, tanto durante el desarrollo, en la zona ventricular embrionaria, donde fue identificado inicialmente (Hecht et al., 1996), como en el cerebro adulto, en la zona subventricular de los ventrículos laterales (observación no publicada) y en el giro dentado del hipocampo (Matas-Rico et al., 2008) le confieren una participación única en los mecanismos de neurogénesis y plasticidad adultos. Sin embargo, hasta ahora, no se han realizado aún estudios en profundidad que permitan conocer adecuadamente su papel en el comportamiento. Esta revisión se centra precisamente en el papel específico del LPA en relación con el comportamiento y sus implicaciones patológicas potenciales en psiquiatría.

\section{Influencia de los receptores de LPA sobre la neuroquímica y fisiología sináptica, base neurobiológica del comportamiento.}

El estudio de ratones modificados genéticamente por deleción, nulos para los receptores de LPA, ha permitido avanzar considerablemente en el estudio de sus funciones en el SNC. El primer ratón nulo para $\mathrm{LPA}_{1}$ se desarrolló con la deleción del exón 3 del gen Lparl, que contenía los dominios que codifican para el sitio de unión del ligando (Contos, Fukushima, Weiner, Kaushal y Chun, 2000) y se caracterizaba por presentar una mortalidad perinatal muy acusada. Los supervivientes mostraban reducción de peso corporal y dimorfismo craneofacial, hocicos cortos, ojos espaciados, menor masa cerebral y, de manera llamativa, déficit en el comportamiento de succión de la mama, debido, probablemente, a una olfacción deficitaria (Contos et al., 2000). Poco tiempo después se publicarían resultados de otro ratón nulo para el receptor $\mathrm{LPA}_{1}$, independiente del primero, por parte de Harrison et al. (2003) y que compartía con aquél los defectos observados, no mostrando ambos ratones ninguna anomalía estructural significativa. Sin embargo, el estudio de Harrison et al. (2003) fue más allá y describió por vez primera alteraciones fenotípicas en relación al comportamiento. Así, el examen de la regulación sensoriomotora, por medio del análisis de la inhibición prepulso (PPI, del inglés prepulse inhibition) de la respuesta a sobresaltos, demostró que los ratones carentes del receptor $\mathrm{LPA}_{1}$ presentaban una menor reducción de la actividad locomotora y un importante déficit en el circuito de reflejo al estímulo, lo que sugería importantes implicaciones para patologías de índole psiquiátrica, como se discutirá detalladamente más adelante.

El grupo de Harrison et al. (2003) valoró, además, la concentración de 5-hidroxitriptamina (5-HT; serotonina), dopamina, así como los metabolitos intermedios de ambos y la composición aminoacídica, encontrando en los animales carentes del receptor $\mathrm{LPA}_{1}$ un importante déficit en la producción de serotonina en numerosas áreas cerebrales que incluían la corteza frontal, el hipocampo, el hipotálamo y el núcleo accumbens, entre otras y, por contra, un incremento de la misma en el estriado. Los niveles de aminoácidos también se vieron reducidos en dichas áreas siendo los cambios mayores en el hipocampo. En posteriores estudios del mismo grupo (Roberts et al., 2005) se detectaron diferencias más específicas que permitieron mostrar un déficit en la liberación inducida de GABA y glutamato $y$, por ende, una menor disponibilidad de dichos neurotransmisores, en el hipocampo de los animales nulos para el receptor $\mathrm{LPA}_{1}$. De manera similar, el patrón resultaba igualmente deficitario para la serotonina en el núcleo dorsal del rafe, lo cual correlacionaba con las anteriores observacio- 
nes de Harrison et al. (2003) mostrando una disminución de producción de serotonina en corteza cerebral e hipocampo, áreas terminales de proyección desde dicho núcleo. Además de la importancia para los estudios de inhibición prepulso, todos estos cambios deberían tener un considerable impacto en estudios comportamentales. Tanto la dopamina como la serotonina están implicadas en el comportamiento de adaptación, toma de decisiones y aprendizaje por refuerzo (Cools, Nakamura y Daw, 2011). Por otra parte, se ha demostrado que la alteración de sistemas serotoninérgicos es capaz de producir efectos comportamentales tales como cambios en la regulación de temperatura, ritmos de vigilia-sueño, emésis, comportamiento sexual, agresividad, nocicepción, balance energético o incluso en el estado de humor (Berger, Gray y Roth, 2009; Jonnakuty y Gragnoli, 2008; Lam et al., 1997; Tecott, 2007; Weiger, 1997). Además, el hipocampo recibe una fuerte inervación serotoninérgica desde el núcleo del rafe, actuando como un importante regulador entre las respuestas del sistema serotoninérgico y neuroendocrina al estrés, y reduciendo así, por ejemplo, los efectos ansiogénicos de los estímulos estresores (Joca, Ferreira y Guimaraes, 2007). Sin embargo, a pesar de todos los cambios neuroquímicos observados en estos animales y sus evidentes implicaciones potenciales en comportamiento, no se pudo demostrar ninguna anomalía en la funcionalidad hipocampal en términos electrofisiológicos o sinápticos.

En este sentido, hace ya unos años, se demostraba que el LPA era capaz de influir la liberación de transmisores en la sinapsis en condiciones ex vivo inhibiendo la actividad de la ATPasa para sodio y potasio en la membrana celular de sinaptosomas de corteza cerebral (Nishikawa, Tomori, Yamashita y Shimizu, 1989). Otros estudios demostrarían, posteriormente, el papel del LPA como activador de la GTPasa Rho en la plasticidad y organización estructural sináptica (Fukushima, Ishii, Habara, Allen y Chun, 2002; Tigyi et al., 1996; Zhang, Schaefer, Burnette, Schoonderwoert y Forscher, 2003) y en neuronas hipocampales (Fujiwara et al., 2003; Jin Rhee et al., 2006; Pilpel y Segal, 2006; Pyka et al., 2011; Tabuchi et al., 2000) donde también participaría en la reorganización de dendritas y axones del hipocampo (Benarroch, 2007). Además, se ha demostrado que el incremento de la actividad de Rho mediado por LPA permite mejorar la memoria espacial a largo plazo (Dash, Orsi,Moody y Moore, 2004). Usando como prueba el laberinto acuático de Morris, Dash et al. (2004) observaron que la administración intrahipocampal de LPA tras el entrenamiento de la tarea lograba que el animal precisara de mucho menos tiempo para localizar la plataforma, y sugerían un nexo funcional entre Rho y el LPA de la misma manera que se ha descrito para otras vías de señalización implicadas en la formación de memoria, tales como la vía de la proteína cinasa $\mathrm{C}$, la mediada por fosfoinositol 3-cinasa, o la vía de la cinasa regulada por señales extracelulares. De hecho, se ha demostrado que los receptores de LPA activan la vía de la proteína cinasa $\mathrm{C}$, aumentando la fosforilación de una isoforma de cinasa de adhe- sión focal (Derkinderen, Siciliano, Toutant y Girault, 1998) y la actividad de los receptores de NMDA en las sinapsis de las neuronas piramidales del hipocampo (Lu et al., 1999), lo que sugiere una función del LPA en la plasticidad sináptica. Los estudios en estos últimos años han puesto de manifiesto un papel del LPA en las sinapsis y la electrofisiología del hipocampo. Cunningham et al. (2006) han mostrado que la ausencia del receptor $\mathrm{LPA}_{1}$ causa una reducción de las oscilaciones de frecuencia alta, o gamma, en las capas superficiales de la corteza entorrinal, a nivel del hipocampo, así como del número de neuronas GABAérgicas. Por otro lado, Musazzi, Daniel, Maycox, Racagni y Popoli (2010), usando sinaptosomas del hipocampo de ratones carentes del receptor $\mathrm{LPA}_{1}$, encontraron una desregulación de las subunidades alfa y beta de la enzima CaMKII a nivel sináptico, donde la enzima, que actúa como un regulador clave en la potenciación a largo plazo y la excitabilidad neuronal (Lisma, Schulman y Cline, 2002), modularía la transmisión glutamatérgica. A nivel postsináptico los animales nulos para LPA mostraban cambios en la interacción de la enzima con los receptores glutamatérgicos ionotrópicos NMDA y AMPA, conductancia alterada en los receptores AMPA y reducción de respuesta en vías de señalización intracelular por NMDA lo que, en conjunto, generaba una mayor reactividad sináptica, combinada con una menor sensibilidad de respuesta al estímulo mediado por vía glutamatérgica, y ponía de manifiesto la disfunción del hipocampo en ausencia del receptor $\mathrm{LPA}_{1}$. Además, a nivel presináptico estos animales mostraban una acumulación de los denominados complejos de proteínas SNARE, mediadores de la fusión de vesículas sinápticas y que tienen relevancia en algunas patologías como la esquizofrenia.

Por otra parte, no la ausencia, sino la sobreexpresión del receptor $\mathrm{LPA}_{1}$ también provoca anomalías sinápticas, observándose cambios morfológicos en las espinas dendríticas de neuronas hipocampales que alteran las propiedades electrofisiológicas del espacio postsináptico, tanto en la cinética de la corriente sináptica como a nivel de composición del canal sináptico (Pilpel y Segal, 2006). Estos cambios estructurales están en consonancia con los estudios que describen en experimentos de cocultivos de neuronas y astrocitos hipocampales cómo la arquitectura de la espina dendrítica puede ser modulada por adición de LPA, facilitando la sinaptogénesis (Pyka et al., 2011). Además, hay que considerar, igualmente, que esos astrocitos, que también expresan receptores de LPA, pueden inducir, o controlar, cambios en la intensidad sináptica a través de la liberación de diferentes gliotransmisores los cuales, a su vez, regulan la densidad postsináptica de receptores AMPA (Bains y Oliet, 2007).

La señalización mediada por LPA en la sinapsis hipocampal implica no solo al receptor $\mathrm{LPA}_{1}$ sino también, por ejemplo, al receptor $\mathrm{LPA}_{2}$, que se ha detectado en terminales presinápticos glutamatérgicos. Muchos de los procesos que participan en la memoria o en la consolidación de la potenciación a largo plazo son activados y regulados por modificaciones en el estado 
de fosforilación de diferentes proteínas cinasas como Erk y CaMKII cuya actividad puede ser también modulada por neurotransmisores como la 5-HT (Cammarota, Bevilaqua, Medina e Izquierdo, 2008). De esta forma, la secuencia orquestada de eventos, así como las consecuencias resultantes en términos de plasticidad neuronal y/o formación de memoria, confieren al LPA un importante papel para ser considerado en cualquier análisis o estudio comportamental.

\section{Papel del receptor $\mathrm{LPA}_{1}$ en el aprendizaje y la memoria}

Hasta estos últimos años y, a excepción de los estudios citados de Dash et al. (2004) y Harrison et al. (2003), no se habían realizado otros en relación a comportamiento o que incluyeran tareas de aprendizaje y memoria. Fue, precisamente, hace poco, cuando un exhaustivo análisis realizado por nuestro grupo (Santín et al., 2009) demostraba la implicación de este receptor en conducta usando una batería de pruebas neurológicas y examinando la habituación, el comportamiento exploratorio en respuesta a ambientes inductores de baja y moderada ansiedad, y la memoria espacial. Este estudio se llevó a cabo sobre ratones nulos para LPA de la variedad Málaga, denominados como maLPA 1 -null (Estivill-Torrús et al., 2008), variante espontánea de la cepa original de Contos et al. (2000). Los ratones maLPA - -null muestran un fenotipo más severo que el original, con una zona ventricular embrionaria reducida en la que la neurogénesis está alterada y que termina por generar una mayor apoptosis cortical y una pared cortical menor (Estivill-Torrús et al., 2008). Estos ratones presentan también defectos en la neurogénesis adulta hipocampal que tiene lugar en el giro dentado, tanto en condiciones basales como tras estimulación por combinación de exposición a enriquecimiento ambiental y ejercicio voluntario, afectándose no solo la propia neurogénesis, sino también la supervivencia y maduración neuronal temprana, particularmente la disposición y ramificación dendrítica, y demostrando influencias específicas del contexto experimental en el adulto sobre los niveles de factores neurotróficos (Matas-Rico et al., 2008). Considerando que las nuevas neuronas que se acaban de formar pueden recibir sinapsis funcionales cuando aun son jóvenes y participar en la formación de nueva memoria (Aimone, Deng y Gage, 2011; Castilla-Ortega, Pedraza, Estivill-Torrús y Santín, 2011; Deng, Aimone y Gage, 2010; Goodman et al., 2010; Macklis, 2001; Shors, 2004; Shors et al., 2001; Van Praag et al., 2002) se puede percibir fácilmente la relevancia de estas deficiencias en el comportamiento, principalmente en memoria.

Así, Santín et al. (2009), en el citado estudio, analizó el papel del receptor $\mathrm{LPA}_{1}$ en funciones sensoriomotoras, emocionales y cognitivas, encontrando, inicialmente y tras usar una amplia batería de pruebas sensoriales estandarizadas (Björklund, Dunnet, Stenevi, Lewuis e Iversen, 1980; Bures, Buresovay Huston, 1983; Marshall y Titelbaum, 1974), que los animales carentes del receptor presentaban déficits neurológicos no severos que afectaban la olfacción, somestesia, refle- jos de extremidades, coordinación y fuerza neuromuscular. En segundo lugar, la ejecución de las pruebas reveló de manera significativa, y en ausencia del receptor LPA, un déficit exploratorio en la prueba de campo abierto y un aumento del comportamiento de tipo ansioso en la prueba del laberinto en cruz elevado. Concretamente, los animales nulos para el receptor realizaban trayectos de menor distancia en la prueba de campo abierto, sin variar la actividad en una segunda exposición al test, es decir, en condiciones de familiaridad vs. novedad. Además, en el laberinto en cruz elevado ejecutaban menos transiciones que los animales control y mostraban, respecto a estos, una notable reducción del índice de ansiedad, medido como el tiempo de permanencia en los brazos abiertos dividido por el tiempo de permanencia tanto en brazos abiertos como cerrados, donde los valores bajos indican niveles elevados de comportamiento de tipo ansioso (Malleret, Hen, Guillou, Segu y Buhot, 1999). Por otra parte, estas respuestas comportamentales pueden ser moduladas directamente o bien por otros factores cuya liberación también está afectada por la ausencia del receptor $\mathrm{LPA}_{1}$, como la serotonina (Harrison et al., 2003). En favor de esta hipótesis habría que considerar la fuerte proyección serotoninérgica que recibe el hipocampo y que le permite activar receptores como el de serotonina de tipo 1A (Chalmers y Watson, 1991; Jacobs y Azmitia, 1992), presente en una alta concentración en el hipocampo de roedores, e implicado en respuestas emocionales como la ansiedad, el estrés, o la depresión (Joca et al., 2007; López, Liberzon, Vázquez, Young y Watson, 1999; Mueller y Beck, 2000; Parks, Robinson, Sibille, Shenk y Toth, 1998; Savitz, Lucki y Drevets, 2009). Las deficiencias comportamentales descritas por Santín et al. se correlacionan, además, con las descritas anteriormente por Harrison et al. (2003), más aún considerando el hecho de que las alteraciones del sistema serotoninérgico son capaces de influir, entre otras pruebas, la ejecución en el laberinto en cruz elevado (Belzung y Griebel, 2001), y apoyan, en definitiva, una regulación dependiente de LPA de los procesos emocionales y moduladores de ansiedad.

Junto a esta implicación en las respuestas emocionales, el estudio de Santín et al. (2009) demostró cómo los ratones Málaga nulos para $\mathrm{LPA}_{1}$, acompañaban estos defectos con otros, igualmente importantes, en memoria espacial. Previamente, Dash et al. (2004) había demostrado, como se ha mencionado, que la administración de LPA en ratas Long-Evans mejoraba la memoria espacial cuando se sometían los animales a las pruebas en el laberinto acuático de Morris. Empleando en los ratones el mismo tipo de laberinto el trabajo de Santín et al. (2009) muestra que la ausencia del receptor LPA no causa un déficit colectivo de aprendizaje espacial, ya que los animales eran capaces de aprender la localización de la plataforma en el agua, pero sí que éstos eran, de manera llamativa, más lentos que los controles, mostrando una retención deficitaria de la memoria espacial y un uso anómalo de las estrategias de búsqueda, con predominio mayoritario de estrategias no espaciales 
sistemáticas y trayectos con bucles repetitivos. Conjuntamente, todos estos resultados ponen de manifiesto que la ausencia del receptor $\mathrm{LPA}_{1}$ desencadena un comportamiento de tipo ansioso y déficits de memoria espacial. No obstante, es difícil excluir si la ansiedad puede interferir el aprendizaje espacial, especialmente en el laberinto acuático de Morris, donde así se ha descrito, siendo el aumento de la tigmotaxis indicativo de tal interferencia (Champagne, Dupuy, Rochford y Poirier, 2002; Whishaw, 1995). Es más, la ejecución de algunas tareas, dependiendo de la cepa de ratón estudiada, puede reflejar un comportamiento más relacionado con ansiedad que con la tarea cognitiva (Dockstader y van der Kooy, 2001; Ohl, Roedel, Storch, Holsboer y Landgraf, 2002), como ocurre, igualmente, cuando se desarrollan patrones anómalos de exploración durante el test (Kameda et al., 2007; Ramos y Mormede, 1998).

Recientemente, nuestro grupo, haciendo uso del análisis de componentes principales, para así estudiar múltiples variantes, ha podido analizar la ansiedad y la memoria espacial en los ratones carentes del receptor $\mathrm{LPA}_{1}$, así como la interrelación entre ambos, para discriminar y excluir la posible influencia de la actividad motora o el comportamiento de tipo ansioso en el aprendizaje. El estudio, llevado a cabo por Castilla-Ortega et al. (2010), empleaba el laberinto de hoyos, habida cuenta de su uso como test de ejecución de tareas de aprendizaje espacial dependientes de hipocampo y donde, de manera similar al laberinto acuático de Morris, se precisan de pistas externas al propio laberinto para resolver la tarea (Oades, 1981). Dicho estudio analizó en cada genotipo y tanto en contexto nuevo, como tras habituación, las interacciones entre las diferentes respuestas estándar de conducta, es decir, la locomoción, la tigmotaxis o permanencia en periferia, la exploración vertical mantenida por las patas traseras (rearing), la introducción exploratoria del hocico en el hoyo (head dipping), la valoración de riesgo, el acicalamiento, y la defecación, así como la memoria de trabajo y de referencia, y la latencia, referida a la localización, por parte del animal, del reforzador en los hoyos. Los ratones maLPA null mostraron una reducción del comportamiento exploratorio ante un contexto novedoso, de acuerdo a lo previamente observado (Santín et al., 2009) y, además, no redujeron la tigmotaxis en un contexto familiar, ni durante el aprendizaje espacial, mostrando un déficit de habituación en todas las variables estudiadas. El estudio por componentes determinaría, posteriormente, la independencia entre la conducta de exploración y el comportamiento de tipo ansioso. Por otro lado, en ausencia del receptor, y durante el último día de aprendizaje, tenía lugar un déficit importante en la memoria de referencia. Además, estos animales mostraban un déficit conforme aumentaba la dificultad de la tarea, principalmente en los intervalos largos entre las pruebas, lo que sugería la implicación del receptor $\mathrm{LPA}_{1}$ en tareas de retención de memoria a largo plazo, específicamente atribuidas a la función del hipocampo (Yoon, Okada, Jung y Kim, 2008). De manera similar, la memoria espacial también se vio afectada tras la deleción del receptor, produciéndose un déficit en la adquisición de reglas procedimentales de memoria de trabajo al inicio y, especialmente, al aumentar el nivel de dificultad de la tarea y el tiempo entre las pruebas, lo que reflejaba un defecto en el aprendizaje gradual de los procedimientos para la correcta ejecución. El estudio de componentes realizado por Castilla-Ortega et al. (2010) en este estudio demostraría, de nuevo, que las conductas que demostraban déficits en las memorias de trabajo y de referencia, eran independientes de los patrones observados de exploración y ansiedad, demostrando la implicación específica del receptor $\mathrm{LPA}_{1}$ en el aprendizaje y en la conducta emocional. Estos resultados se correlacionan, además, con los mostrados por Matas-Rico et al. (2008) ya que tanto la neurogénesis adulta como los factores neurotróficos relacionados, alterados en ausencia del receptor, se han relacionado frecuentemente con las memorias de trabajo y de referencia (Aimone et al., 2011; Castilla-Ortega et al., 2011; Deng et al., 2010; Goodman et al., 2010; Leuner, Gould y Shors, 2006; Macklis, 2001; Mizuno, Yamada, He, Nakajima y Nabeshima, 2003; Saxe et a., 2007; Shors, 2004; Shors et al., 2001; Tyler, Alonso, Bramham y Pozzo-Miller, 2002; Van Praag et al., 2002.

\section{Implicación del receptor $\mathrm{LPA}_{1}$ en patologías psiquiátricas}

La mayor parte de la investigación en lisofosfolípidos llevada a cabo estos últimos años ha puesto de manifiesto el papel del LPA a través de sus receptores, principalmente el LPA, en numerosos procesos cerebrales, tanto durante el desarrollo como en la etapa adulta. La vía de señalización por LPA 1 , participante necesaria en el desarrollo cerebral, en la modulación de conductas de tipo ansioso, o en tareas cognitivas dependientes de hipocampo, se muestra así como una vía con un enorme potencial de implicación en patologías de índole neuropsiquiátrico o cognitivo, particularmente en aquellas que, por ejemplo, se encuentran asociadas a un neurodesarrollo anómalo, como la esquizofrenia o el autismo, o aquellas otras, desencadenadas por factores ambientales, como el estrés, que son mediadas también por la interacción con factores de predisposición o genéticos, afectando a la conducta cognitiva.

Las enfermedades asociadas a trastornos del neurodesarro1lo, como la esquizofrenia o el autismo, son enfermedades complejas donde la patología es el resultado final de una interacción prolongada entre factores ambientales y factores genéticos. No ha sido hasta estos últimos años cuando la esquizofrenia ha empezado a ser considerada un trastorno del neurodesarrollo. Su etiología aún está por averiguar en profundidad, pese a los estudios que inciden en su heredabilidad y en su origen genético (Allan, Cardno y McGuffin, 2008; Cardno y Gottestman, 2000), siendo decisivos los mecanismos durante el desarrollo (Norton, Williams y Owen, 2006; Ross et al., 2010; Weinberger, 1987). Además, los déficits cognitivos asociados a la esquizofrenia (déficit en memoria de procedimiento, déficit de atención, habla incoherente, perseveración) son estables durante el curso de la enfermedad y se desarrollan mucho antes de que aparezcan los síntomas positivos (alucinaciones, paranoia, deli- 
rios) o negativos (pérdida o alteraciones del afecto, la voluntad, o el deseo del placer) de la misma (Tamminga y Holcomb, 2005). La hipótesis del desarrollo para la esquizofrenia asume que, durante la gestación, hay factores patogénicos previos al comienzo de la enfermedad y que alteran el desarrollo normal neural, generando alteraciones de circuitos neuronales específicos y confiriendo la vulnerabilidad necesaria para desencadenar la patología. Esta hipótesis se basa tanto en las observaciones que describen alteraciones estructurales a modo de las que afectan a la circuitería (Fallon, Opole y Potkin, 2003), volumen cortical (Wright et al., 2000) o anomalías oligodendrocitarias y de sustancia blanca (Tkachev et al., 2003; Whitford et al., 2010), como en las asociaciones que muestran genes y factores, generalmente necesarios para la neurogénesis y la plasticidad, que confieren susceptibilidad a la patología (Gogos y Gerber, 2006).

En este sentido, y durante los últimos años, se ha sugerido la vía de señalización mediada por el receptor $\mathrm{LPA}_{1}$ como una nueva vía que puede estar implicada en la esquizofrenia, a la vista de estar involucrada en dos de los procesos afectados en la patología, el desarrollo del sistema nervioso central y la mielinización, en fase postnatal (Desbonnet, Waddington y Tuathaigh, 2009). Así, el ratón carente del receptor $\mathrm{LPA}_{1}$ ha ganado interés como modelo de esta patología (Bowden et al., 2006; Desbonnet et al., 2009; Harrison et al., 2003; Murph, Nguyen, Radhakrishna y Mills, 2008; Roberts et al., 2005; Van den Buuse, 2010), especialmente una vez que se ha mostrado que el gen que codifica al receptor en el hombre, LPARl, se encuentra en un pequeño grupo de genes con una estrecha asociación con la patología, estando regulado a la baja en los pacientes (Bowden et al., 2006). El ratón nulo para el receptor $\mathrm{LPA}_{1}$ comparte rasgos comunes con la enfermedad. Así, la deleción en homocigosis del receptor en diferentes cepas causa dimorfismo craneofacial (Contos et al., 2000; Estivill-Torrús et al., 2008; Harrison et al., 2003), reducción de volumen cortical y alteración del desarrollo cortical (Estivill-Torrús et al., 2008), defecto de la neurogénesis hipocampal (Matas-Rico et al., 2008), anomalías en la mielinización postnatal (Contos et al., 2000), modificación de los niveles de los complejos de proteínas sinápticas SNARE (Musazzi et al., 2010) y, de manera notable, disminución de la síntesis de serotonina y de la neurotransmisión por GABA y glutamato (Harrison et al., 2003; Murph et al., 2008, Roberts et al., 2005), así como alteración de los circuitos GABAérgicos (Cunningham et al., 2006). Este amplio conjunto de defectos configura un fenotipo de anomalías cerebrales estructurales y neuroquímicas que se asemeja en gran medida al descrito en la esquizofrenia y en otros modelos murinos aceptados de la patología (Abi-Dargham, Laruelle, Aghajanian, Charney y Krystal, 1997; Akbarian et al., 1993; Ayhan, Sawa, Ross y Pletnikov, 2009; Benes y Berretta, 2001; Benes, Todtenkopf y Kostoulakos, 2001; Bressan y Pilowsky, 2000; Hennessy, Baldwin, Browne, Kinsella y Waddington, 2007; Honer et al., 2002; Karoutzou, Emrich y Dietrich, 2008;
Inta, Monyer, Sprengel, Meyer-Lindenberg y Gass, 2010; Kim, Kornhuber, Schmid-Burgk y Holzmuller, 1980; Noorbala, Akhondzadeh, Davari-Ashtiani y Amini-Nooshabedi, 1999; Ohnuma, Augood, Arai, McKenna y Emson, 1999; Selemon y Goldman-Rakic, 1999; van Haren et al., 2008).

En los animales modificados genéticamente, al no ser posible la determinación de los síntomas positivos y negativos de una persona, por su especificidad, las pruebas de comportamiento para evaluar los síntomas de una esquizofrenia se centran únicamente en observar si presenta hiperactividad locomotora y déficit de la regulación sensoriomotora. Éste último se mide a través del análisis de la inhibición prepulso de la respuesta a sobresaltos, usando un estímulo acústico de alta intensidad, precedido por uno de baja intensidad (Braff, Geyer y Swerdlow, 2001; Geyer, Krebs-Thomson, Braff y Swerdlow, 2001; Hoffman e Ison, 1980), y permite analizar la respuesta en el modelo animal de una manera muy similar a la metodología empleada en pacientes. La alteración de la inhibición por prepulso se ha observado en cualquier modelo propuesto de esquizofrenia y está presente tanto en pacientes bajo tratamiento como a nivel basal en esquizofrénicos (Braff et al., 2001). En los ratones carentes del receptor $\mathrm{LPA}_{1}$ las alteraciones comportamentales son similares a la sintomatología positiva y negativa, así como al déficit cognitivo, que se observan en la esquizofrenia (Arguello y Gogos, 2010; Cosoff y Hafner, 1998; Van de Buuse, 2010; Wolff y O’Driscoll, 1999). Así, los ratones nulos para $\mathrm{LPA}_{1}$ muestran una reducción anómala de la inhibición prepulso tras el estímulo, déficit motor, reducción de conducta exploratoria, defectos en la memoria de referencia espacial, uso de estrategias repetitivas, aumento del comportamiento de tipo ansioso y defectos de memoria de trabajo en tareas que requieren el aprendizaje de la regla operativa (Castilla-Ortega et al., 2010; Harrison et al., 2003; Santín et al., 2009). Igualmente, la alteración de la neurogénesis hipocampal está presente tanto en los pacientes esquizofrénicos (Kempermann, Krebs y Fabel, 2008; Reif et al., 2006) como en los ratones Málaga nulos para LPA $_{1}$ (Matas-Rico et al, 2008) y cobra relevancia en algunos de los déficits cognitivos, como aquellos relativos a la memoria espacial dependiente de hipocampo (Coras et al., 2010; Goodman et al., 2010; Koehl y Abrous, 2011; Leuner, Gould y Shors, 2006). En este sentido, algunos autores han propuesto un modelo de interacción gen-ambiente en el que una variante en un gen relacionado con la neurogénesis y un factor ambiental conferirían vulnerabilidad y generarían una respuesta de factores que desencadenarían, a su vez, un déficit neurogénico que causara, finalmente, la esquizofrenia (Le Strat, Ramoz y Gorwood, 2009). Todos estos resultados sugieren que la expresión anómala del gen LPAR1 en el sujeto puede estar implicada o contribuir a la exacerbación de los síntomas cognitivos de la esquizofrenia y proporcionar susceptibilidad para el desarrollo de la enfermedad.

Se ha sugerido que el LPA puede contribuir al desarrollo de otros trastornos psiquiátricos, más allá de la esquizofrenia, 
especialmente por el defecto que la deleción del receptor $\mathrm{LPA}_{1}$ genera en la neurotransmisión mediada por serotonina (Harrison et al., 2003), diana de numerosos fármacos antipsicóticos y antidepresivos. Algunos autores han sugerido que en los ratones nulos para LPA, la exposición cerebral al LPA circulante, a través de las hemorragias que presentan, podría tener un efecto en el microambiente cerebral y contribuir a la patología, tal y como ocurre en enfermedades donde la pérdida de sangre materna o fetal prenatal se asocia a la sintomatología, como en la esquizofrenia o el autismo. De hecho, el crecimiento cortical mediado por la exposición a LPA descrito in vitro, semejante al proceso de girificación que concurre en ambas patologías, apoyaría esta hipótesis (Choi et al., 2008; Kingsbury et al., 2003). También se ha demostrado que el LPA puede inhibir los efectos celulares que en la astroglia son mediados por la risperidona, un neuroléptico usado para mejorar los síntomas del autismo (Quincozes-Santos et al., 2008). Otros autores han relacionado al LPA con el trastorno bipolar de tipo I debido a las observaciones que describen una respuesta más rápida de movilización de calcio estimulada por LPA en líneas celulares de linfoblastos B de pacientes con dicho trastorno (Perova, Wasserman, Li y Warsh, 2008) de acuerdo a las anomalías en la dinámica del calcio intracelular presentes en la fisiopatología del trastorno bipolar (Emamghoreishi et al., 1997). Dicha respuesta a LPA puede, a su vez, ser modificada y atenuada con estabilizadores del ánimo como el litio o el valproato (Perova, Kwan, Li y Warsh, 2010). Muchos datos, en definitiva, relacionan al LPA con mecanismos presentes en las patologías de tipo psiquiátrico. Hasta la fecha, se ha demostrado que el LPA es un factor clave de diferentes mecanismos de transducción de señal en una amplia variedad de células y tejidos, tanto en estado normal como patologico. A pesar de las numerosas cuestiones aún por responder en relación a la función que desempeña el LPA en la patogenia de trastornos del comportamiento y psiquiátricos, estas investigaciones aportan nueva e interesante información que sumar a los estudios en curso para el diseño de terapias efectivas.

Por otra parte, es preciso contar, además, con los factores externos, ambientales, que pueden contribuir al desarrollo de patologías y trastornos de la conducta. El estrés juega, en este sentido, un importante papel en el desarrollo y exacerbación de las enfermedades psiquiátricas. El estrés se podría definir, entre otras acepciones, como el modo en que el cuerpo y la mente reaccionan ante un acontecimiento que desestabiliza el equilibrio normal en nuestra vida. El estrés a corto plazo, o agudo, implica una respuesta inmediata ante cualquier situación que se entiende como imperativa o peligrosa. Generalmente el cuerpo se recupera rápidamente de este tipo de estrés, si bien depende de la frecuencia de exposición al estresor. El estrés crónico, por contra, es un proceso a largo plazo causado por situaciones estresantes o acontecimientos diarios que permanecen por un largo periodo de tiempo y con un impacto perjudicial considerable en nuestra salud. Los estresores, que actúan de manera adversa en nuestra vida diaria, junto al estado emocional del individuo, pueden alterar significativamente nuestra fisiología, especialmente a nivel cerebral. En nuestra sociedad el estrés continuo es bastante frecuente y las consecuencias patológicas están bien documentadas, generando alteraciones emocionales y cognitivas acompañadas de defectos en la neurogénesis hipocampal (Gould y Tanapat, 1999; Henckens, Hermans, Pu, Jöels y Fernandez, 2009; Jöels y Baram, 2009; Jöels, Fernández y Roozendaal, 2001; Jöels, Karst, Krugers y Lucassen, 2007; McEwen, 2000; Pittenger y Duman, 2008; Schwabe, Jöels, Roozendaal, Wolf y Oitzl, 2011; Warner-Schmidt y Durnan, 2006). Por otro lado, los defectos en neurogénesis constituyen un elemento determinante en patologías psiquiátricas como la depresión o la esquizofrenia y pueden explicar la contribución del estrés a su desarrollo (Kempermann, Krebs y Fabel, 2008; Pittenger y Duman, 2008; Warner-Schmidt y Durnan, 2006). Recientemente, además de las funciones previamente descritas, hemos obtenido resultados que indican que la vía de señalización mediada por LPA 1 actúa como importante modulador de los efectos del estrés crónico sobre la neurogénesis hipocampal y la memoria espacial (Castilla-Ortega et al., 2011). El estudio se basa en el papel que presenta el receptor LPA $_{1}$ en la neurogénesis adulta del hipocampo y en el efecto del estrés crónico sobre ésta, en términos de plasticidad estructural. Así, el receptor $\mathrm{LPA}_{1}$ podría, igualmente, regular el impacto del estrés crónico sobre la neurogénesis del giro dentado y la conducta dependiente de hipocampo, y su falta conferiría vulnerabilidad al estrés crónico. El empleo del laberinto de hoyos, como prueba de evaluación, en combinación con el estrés por inmovilización, como modelo experimental, nos ha permitido demostrar que la ausencia del receptor $\mathrm{LPA}_{1}$ en los ratones Málaga nulos para LPA 1 aumenta la severidad de los efectos adversos del estrés crónico sobre la proliferación celular, apoptosis, maduración neuronal, volumen, y densidad neuronal de la zona granular del hipocampo. Estas deficiencias se correlacionan, en estos animales, con un importante déficit en la consolidación de la memoria de referencia espacial, en contraste con el efecto mucho menor del estrés crónico en los animales normales. El estudio demuestra que el estrés crónico aumenta la severidad de los defectos dependientes del receptor LPA $y$ que una carencia o una deficiencia en la expresión del receptor aportarían mayor vulnerabilidad al estrés crónico, precipitando la patología hipocampal. Estos resultados también apoyan la conveniencia de usar animales nulos para los receptores de LPA en los estudios de las interacciones genético-ambientales con relevancia en psiquiatría, tanto por la implicación propuesta del receptor $\mathrm{LPA}_{1}$ en la esquizofrenia, como por la vulnerabilidad a estrés que se muestra en dicha patología (Norman y Malla, 1993).

Como se ha mencionado anteriormente, la señalización por LPA está implicada en numerosos procesos cerebrales que afectan a la función cerebral incluyendo, también, el comportamiento. Los estudios citados subrayan el papel que el LPA 
juega en el comportamiento haciendo uso de una variada tecnología que incluye técnicas bioquímicas, genéticas, histológicas, o pruebas comportamentales. La complejidad de las interacciones entre las diferentes estructuras cerebrales, su regulación endocrina, modulación ambiental, o los factores genéticos o de predisposición que las condicionan, hacen necesarios futuros estudios para delimitar la función de esta vía de señalización en cada circunstancia. Aunque, indudablemente, estos resultados abren vías para abordar nuevas intervenciones en psicopatología, el amplio rango de efectos sobre el comportamiento in vivo, su relevancia para los trastornos psiquiátricos y su potencial terapéutico nos obligan a ser cautos en la interpretación de los resultados y a trabajar en diferentes diseños experimentales que deben incluir, tanto los modelos animales carentes del receptor, como una adecuada modulación farmacológica de los receptores.

\section{Referencias}

1. Abi-Dargham, A., Laruelle, M., Aghajanian, G.K., Charney, D. y Krystal, J. (1997). The role of serotonin in the pathophysiology and treatment of schizophrenia. Journal of Neuropsychiatry and Clinical Neurosciences, 9, 1-17.

2. Aimone, J.B., Deng, W. y Gage, F.H. (2011). Resolving new memories: a critical look at the dentate gyrus, adult neurogenesis, and pattern separation. Neuron, 70, 589-596. http://dx.doi.org/10.1016/j.neuron.2011.05.010

3. Akbarian, S., Bunney, W.E., Jr., Potkin, S.G., Wigal, S.B., Hagman, J.O., Sandman, C.A. y Jones, E.G. (1993). Altered distribution of nicotinamide-adenine dinucleotide phosphate-diaphorase cells in frontal lobe of schizophrenics implies disturbances of cortical development. Archives of General Psychiatry, 50, 169-177.

4. Allan, C.L., Cardno, A.G. y McGuffin, P. (2008). Schizophrenia: from genes to phenes to disease. Current Psychiatry Reports, 10, 339-343. http://dx.doi.org/10.1007/s11920008-0054-X

5. Anliker, B. y Chun, J. (2004). Lysophospholipid G proteincoupled receptors. Journal of Biological Chemistry, 279, 20555-20558. http://dx.doi.org/10.1074/jbc.R400013200

6. Aoki, J. (2004). Mechanisms of lysophosphatidic acid production. Seminars in Cell \& Developmental Biology, 15, 477-489. http://dx.doi.org/10.1016/j.semcdb.2004.05.001

7. Aoki, J., Inoue, A. y Okudaira, S. (2008). Two pathways for lysophosphatidic acid production. Biochimica et Biophysica Acta, 178, 513-518.

8. Arguello, P.A. y Gogos, J.A. (2010). Cognition in mouse models of schizophrenia susceptibility genes. Schizophrenia Bulletin, 36, 289-300. http://dx.doi.org/10.1093/schbul/ sbp153

9. Ayhan, Y., Sawa, A., Ross, C.A. y Pletnikov, M.V. (2009). Animal models of gene-environment interactions in schizophrenia. Behavioral Brain Research, 204, 274-281. http:// dx.doi.org/10.1016/j.bbr.2009.04.010
10. Bains, J.S. y Oliet, S.H. (2007). Glia: they make your memories stick! Trends in Neurosciences, 30, 417-424. http://dx.doi.org/10.1016/j.tins.2007.06.007

11. Belzung, C. y Griebel, G. (2001). Measuring normal and pathological anxiety-like behaviour in mice: a review. Behavioral Brain Research, 125, 141-149. http://dx.doi. org/10.1016/S0166-4328(01)00291-1

12. Benarroch, E.E. (2007). Rho GTPases: role in dendrite and axonal growth, mental retardation, and axonal regeneration. Neurology, 68, 1315-1318. http://dx.doi.org/10.1212/01. wnl.0000259588.97409.8f

13. Benes, F.M. y Berretta, S. (2001). GABAergic interneurons: implications for understanding schizophrenia and bipolar disorder. Neuropsychopharmacology, 25, 1-27. http://dx.doi.org/10.1016/S0893-133X(01)00225-1

14. Benes, F.M., Todtenkopf, M.S. y Kostoulakos, P. (2001). GluR5,6,7 subunit immunoreactivity on apical pyramidal cell dendrites in hippocampus of schizophrenics and manic depressives. Hippocampus, 11, 482-491. http://dx.doi. org/10.1002/hipo.1065

15. Berger, M., Gray, J.A. y Roth, B.L. (2009). The expanded biology of serotonin. Annual Review of Medicine, 60, 355-336. http://dx.doi.org/10.1146/annurev. med.60.042307.110802

16. Birgbauer, E. y Chun, J. (2006). New developments in the biological functions of lysophospholipids. Cellular and Molecular Life Sciences, 63, 2695-2701. http://dx.doi. org/10.1007/s00018-006-6155-y

17. Björklund, A., Dunnet, S.B., Stenevi, U., Lewuis, M.E. e Iversen, S.D. (1980). Reinervation of the denervate striatum by substantia nigra. Brain Research, 199, 307-333.

18. Bowden, N.A., Weidenhofer, J., Scott, R.J., Schall, U., Todd, J., Michie, P.T. y Tooney, P.A. (2006). Preliminary investigation of gene expression profiles in peripheral blood lymphocytes in schizophrenia. Schizophrenia Research, 82, 175-183. http://dx.doi.org/10.1016/j.schres.2005.11.012

19. Braff, D.L., Geyer, M.A., y Swerdlow, N.R. (2001). Human studies of prepulse inhibition of startle: normal subjects, patient groups, and pharmacological studies. Psychopharmacology, 156, 234-258. http://dx.doi.org/10.1007/ $\underline{\mathrm{s} 002130100810}$

20. Bressan, R.A y Pilowsky, L.S. (2000). Imaging the glutamatergic system in vivo--relevance to schizophrenia. European Journal of Nuclear Medicine, 27, 1723-1731. http:// dx.doi.org/10.1007/s002590000372

21. Bures, J., Buresova, O. y Huston, J.P. (1983). Techniques and basic experiments for the study of brain and behaviour. Elsevier Science Publishers: Amsterdam.

22. Cammarota, M., Bevilaqua, L.R., Medina, J.H. e Izquierdo I. (2008). ERK1/2 and CaMKII-mediated events in memory formation: is 5HT regulation involved? Behavioral Brain Research, 195, 120-128. http://dx.doi.org/10.1016/j. bbr.2007.11.029 
23. Cardno, A.G. y Gottesman, I.I. (2000). Twin studies of schizophrenia: from bow-and-arrow concordances to star wars Mx and functional genomics. American Journal of Medicine and Genetics, 97, 12-17. http://dx.doi. org/10.1002/(SICI)1096-8628(200021)97:1<12::AIDAJMG3>3.0.CO;2-U

24. Castilla-Ortega, E., Sanchez-Lopez, J., Hoyo-Becerra, C., Matas-Rico, E., Zambrana-Infantes, E., Chun, J., De Fonseca, F.R., Pedraza, C., Estivill-Torrús, G. y Santín, L.J. (2010). Exploratory, anxiety and spatial memory impairments are dissociated in mice lacking the LPA1 receptor. Neurobiology of Learning and Memory, 94, 73-82. http:// dx.doi.org/10.1016/j.nlm.2010.04.003

25. Castilla-Ortega, E., Pedraza, C., Estivill-Torrús, G. y Santín, L.J. (2011). When is adult hippocampal neurogenesis necessary for learning? Evidence from animal research. Reviews in Neuroscience, 22, 267-283. http://dx.doi. org/10.1515/RNS.2011.027

26. Castilla-Ortega, E., Hoyo-Becerra, C., Pedraza, C., Chun, J., Rodríguez de Fonseca, F., Estivill-Torrús, G. y Santín, L.J. (2011). Aggravation of the Pathological Consequences of Chronic Stress on Hippocampal Neurogenesis and Spatial Memory in Mice Lacking the Lysophosphatidic Acid LPA1 Receptor. PLoS ONE 6: e25522. http://dx.doi. org/10.1371/journal.pone.0025522

27. Chalmers, D.T. y Watson, S.J. (1991). Comparative anatomical distribution of 5-HT1A receptor mRNA and 5-HT1A binding in rat brain - a combined in situ hybridisation/in vitro receptor autoradiographic study. Brain Research, 561, 51-60. http://dx.doi.org/10.1016/0006-8993(91)90748-K

28. Champagne, D., Dupuy, J.B., Rochford, J. y Poirier, J. (2002). Apolipoprotein E knockout mice display procedural deficits in the morris water maze: analysis of learning strategies in three versions of the task. Neuroscience, 114, 641654. http://dx.doi.org/10.1016/S0306-4522(02)00313-5

29. Choi, J.W., Lee, C.W. y Chun, J. (2008). Biological roles of lysophospholipid receptors revealed by genetic null mice: an update. Biochimica et Biophysica Acta, 1781, 531-539. http://dx.doi.org/10.1016/j.bbalip.2008.03.004

30. Choi, J.W., Herr, D.R., Noguchi, K., Yung, Y.C., Lee, C.W., Mutoh, T., Lin, M.E., Teo, S.T., Park, K.E., Mosley, A.N. y Chun, J. (2010). LPA receptors: subtypes and biological actions. Annual Review of Pharmacology and Toxicology, 50, 157-186. http://dx.doi.org/10.1146/annurev.pharmtox.010909.105753

31. Chun, J. (2005). Lysophospholipids in the nervous system. Prostaglandins and Other Lipid Mediators, 77, 46-51. http://dx.doi.org/10.1016/j.prostaglandins.2004.09.009

32. Chun J. (2007). How the lysophospholipid got its receptor. The Scientist, 21, 48-54.

33. Chun, J., Weiner, J.A., Fukushima, N., Contos, J.J., Zhang, G., Kimura, Y., Dubin, A., Ishii, I., Hecht, J.H., Akita, C., Kaushal, D. (2000). Neurobiology of receptor-mediated lysophospholipid signaling. From the first lysophospholipid receptor to roles in nervous system function and development. Annals of the New York Academy of Sciences, 905, 110-117. http://dx.doi.org/10.1111/j.1749-6632.2000. tb06543.x

34. Chun, J., Hla, T., Lynch, K.R., Spiegel, S. y Moolenaar, W.H. (2010). International Union of Basic and Clinical Pharmacology. LXXVIII. Lysophospholipid receptor nomenclature. Pharmacological Reviews, 62, 579-587. http://dx.doi.org/10.1124/pr.110.003111

35. Contos, J.J., Fukushima, N., Weiner, J.A., Kaushal, D. y Chun, J. (2000). Requirement for the lpA1 lysophosphatidic acid receptor gene in normal suckling behavior. Proceedings of the National Academy of Sciences USA, 97, 1338413389. http://dx.doi.org/10.1073/pnas.97.24.13384

36. Cools, R., Nakamura, K. y Daw, N.D. (2011). Serotonin and dopamine: unifying affective, activational, and decision functions. Neuropsychopharmacology, 36, 98-113. http://dx.doi.org/10.1038/npp.2010.121

37. Coras, R., Siebzehnrubl, F.A., Pauli, E., Huttner, H.B., Njunting, M., Kobow, K., et al. (2010). Low proliferation and differentiation capacities of adult hippocampal stem cells correlate with memory dysfunction in humans. Brain, 133, 3359-3372. http://dx.doi.org/10.1093/brain/awq215

38. Cosoff, S.J. y Hafner, R.J. (1998). The prevalence of comorbid anxiety in schizophrenia, schizoaffective disorder and bipolar disorder. Australian and New Zealand Journal of Psychiatry, 32, 67-72. http://dx.doi. org/10.3109/00048679809062708

39. Cunningham, M.O., Hunt, J., Middleton, S., LeBeau, F.E., Gillies, M.J., Davies, C.H. y Maycox, P.R., Whittington M.A., Racca C. (2006). Region-specific reduction in entorhinal gamma oscillations and parvalbumin-immunoreactive neurons in animal models of psychiatric illness. Journal of Neuroscience, 26, 2767-2776. http://dx.doi.org/10.1523/ JNEUROSCI.5054-05.2006

40. Dash, P.K., Orsi, S.A., Moody, M. y Moore, A.N. (2004). A role for hippocampal Rho-ROCK pathway in long-term spatial memory. Biochemical and Biophysical Research Communications, 322, 893-898. http://dx.doi.org/10.1016/j. bbrc.2004.08.004

41. Deng, W., Aimone, J.B. y Gage, F.H. (2010). New neurons and new memories: how does adult hippocampal neurogenesis affect learning and memory? Nature Reviews in Neuroscience, 11, 339-350. http://dx.doi.org/10.1038/nrn2822

42. Derkinderen, P., Siciliano, J., Toutant, M. y Girault, J.A. (1998). Differential regulation of FAK+ and PYK2/ Cakbeta, two related tyrosine kinases, in rat hippocampal slices: effects of LPA, carbachol, depolarization and hyperosmolarity. European Journal of Neuroscience, 10, 16671675. http://dx.doi.org/10.1046/j.1460-9568.1998.00174.x

43. Desbonnet, L., Waddington, J.L. y Tuathaigh, C.M. (2009). Mice mutant for genes associated with schizo- 
phrenia: common phenotype or distinct endophenotypes? Behavioral Brain Research, 204, 258-273. http://dx.doi. org/10.1016/j.bbr.2009.04.001

44. Dockstader, C.L. y van der Kooy, D. (2001). Mouse strain differences in opiate reward learning are explained by differences in anxiety, not reward or learning. Journal of Neuroscience, 21, 9077-9081.

45. Emamghoreishi, M., Schlichter, L., Li, P.P., Parikh, S., Sen, J., Kamble, A. y Warsh, J.J. (1997). High intracellular calcium concentrations in transformed lymphoblasts from subjects with bipolar I disorder. American Journal of Psychiatry, 154, 976-982.

46. Estivill-Torrús, G., Llebrez-Zayas, P., Matas-Rico, E., Santín, L., Pedraza, C., De Diego, I., Del Arco, I., Fernández-Llebrez, P., Chun, J. y De Fonseca, F.R. (2008). Absence of LPA1 signaling results in defective cortical development. Cerebral Cortex, 18, 938-950.

47. Fallon, J.H., Opole, I.O. y Potkin, S.G. (2003). The neuroanatomy of schizophrenia: circuitry and neurotransmitter systems. Clinical Neuroscience Research, 3, 77-107. http:// dx.doi.org/10.1016/S1566-2772(03)00022-7

48. Fujiwara, Y., Sebok, A., Meakin, S., Kobayashi, T., Murakami- Murofushi, K. y Tigyi, G. (2003). Cyclic phosphatidic acid elicits neurotrophin-like actions in embryonic hippocampal neurons. Journal of Neurochemistry, 87, 1272-1283. http://dx.doi.org/10.1046/j.14714159.2003.02106.x

49. Fukushima, N., Ishii, I., Habara, Y., Allen, C.B. y Chun, J. (2002). Dual regulation of actin rearrangement through lysophosphatidic acid receptor in neuroblast cell lines: actin depolymerization by $\mathrm{Ca}(2+)$-alpha-actinin and polymerization by rho. Molecular Biology of the Cell, 13, 26922705. http://dx.doi.org/10.1091/mbc.01-09-0465

50. Fukushima, N., Ye, X. y Chun, J. (2002). Neurobiology of lysophosphatidic acid signaling. Neuroscientist, 8, 540550. http://dx.doi.org/10.1177/1073858402238513

51. Geyer, M.A., Krebs-Thomson, K., Braff, D.L. y Swerdlow, N.R. (2001). Pharmacological studies of prepulse inhibition models of sensorimotor gating deficits in schizophrenia: a decade in review. Psychopharmacology, 156, 117154. http://dx.doi.org/10.1007/s002130100811

52. Gogos, J.A. y Gerber, D.J. (2006). Schizophrenia susceptibility genes: emergence of positional candidates and future directions. Trends in Pharmacological Sciences, 27, 226233. http://dx.doi.org/10.1016/j.tips.2006.02.005

53. Goldshmit, Y., Munro, K., Yuen Leong, S., Pébay, A. y Turnley, A.M. (2010). LPA receptor expression in the central nervous system in health and following injury. Cell and Tissue Research, 341, 23-32. http://dx.doi.org/10.1007/ s00441-010-0977-5

54. Goodman, T., Trouche, S., Massou, I., Verret, L., Zerwas, M., Roullet, P. y Rampon, C. (2010). Young hippocampal neurons are critical for recent and remote spatial memory in adult mice. Neuroscience, 171, 769-778. http://dx.doi. org/10.1016/j.neuroscience.2010.09.047

55. Gould, E. y Tanapat, P. (1999). Stress and hippocampal neurogenesis. Biological Psychiatry, 46, 1472-1479. http:// dx.doi.org/10.1016/S0006-3223(99)00247-4

56. Harrison, S.M., Reavill, C., Brown, G., Brown, J.T., Cluderay, J.E., Crook, B., Davies, C.H., Dawson, L.A., Grau, E., Heidbreder, C., Hemmati, P., Hervieu, G., Howarth, A., Hughes, Z.A., Hunter, A.J., Latcham, J., Pickering, S., Pugh, P., Rogers, D.C., Shilliam, C.S. y Maycox, P.R. (2003). LPA1 receptor-deficient mice have phenotypic changes observed in psychiatric disease. Molecular and Cellular Neuroscience, 24, 1170-1179. http://dx.doi. org/10.1016/j.mcn.2003.09.001

57. Hecht, J.H., Weiner, J.A., Post, S.R. y Chun, J. (1996). Ventricular zone gene-1 (vzg-1) encodes a lysophosphatidic acid receptor expressed in neurogenic regions of the developing cerebral cortex. Journal of Cell Biology, 135, 10711083. http://dx.doi.org/10.1083/jcb.135.4.1071

58. Henckens, M.J., Hermans, E.J., Pu, Z., Joëls, M. y Fernández, G. (2009). Stressed memories: how acute stress affects memory formation in humans. Journal of Neuroscience, 29, 10111-10119. http://dx.doi.org/10.1523/JNEUROSCI.1184-09.2009

59. Hennessy, R.J., Baldwin, P.A., Browne, D.J., Kinsella, A. y Waddington, J.L. (2007). Three-dimensional laser surface imaging and geometric morphometrics resolve frontonasal dysmorphology in schizophrenia. Biological Psychiatry, 61, 1187-1194. http://dx.doi.org/10.1016/j.biopsych.2006.08.045

60. Hoffman, H.S. e Ison, J.R. (1980). Reflex modification in the domain of startle: I. Some empirical findings and their implications for how the nervous system processes sensory input. Psychological Reviews, 87, 175-189. http://dx.doi. org/10.1037/0033-295X.87.2.175

61. Honer, W.G., Falkai, P., Bayer, T.A., Xie, J., Hu, L., Li, H.Y., Arango, V., Mann, J.J., Dwork, A.J. y Trimble, W.S. (2002). Abnormalities of SNARE mechanism proteins in anterior frontal cortex in severe mental illness. Cerebral Cortex, 12, 349-356. http://dx.doi.org/10.1093/cercor/12.4.349

62. Inta. D., Monyer, H., Sprengel, R., Meyer-Lindenberg, A. y Gass, P. (2010). Mice with genetically altered glutamate receptors as models of schizophrenia: A comprehensive review. Neuroscience \& Biobehavioral Reviews, 34, 285294. http://dx.doi.org/10.1016/j.neubiorev.2009.07.010

63. Ishii, I., Fukushima, N., Ye, X. y Chun, J. (2004). Lysophospholipid receptors: signaling and biology. Annual Reviews of Biochemistry, 73, 321-354. http://dx.doi.org/10.1146/ annurev.biochem.73.011303.073731

64. Jacobs, B.L. y Azmitia, E.C. (1992). Structure and function of the brain serotonin system. Physiological Reviews, 72, 165-229.

65. Jin Rhee, H., Nam, J.S., Sun, Y., Kim, M.J., Choi, H.K., 
Han, D.H., Kim, N.H. y Huh, S.O. (2006). Lysophosphatidic acid stimulates cAMP accumulation and cAMP response element-binding protein phosphorylation in immortalized hippocampal progenitor cells. Neuroreport, 17, 523-526. http://dx.doi.org/10.1097/01.wnr.0000209011.16718.68

66. Joca, S.R., Ferreira, F.R. y Guimaraes, F.S. (2007). Modulation of stress consequences by hippocampal monoaminergic, glutamatergic and nitrergic neurotransmitter systems. Stress, 10, 227-249. http://dx.doi. org/10.1080/10253890701223130

67. Joels, M., Karst, H., Krugers, H.J. y Lucassen, P.J. (2007). Chronic stress: implications for neuronal morphology, function and neurogenesis. Frontiers in $\mathrm{Neu}$ roendocrinology, 28, 72-96. $\mathrm{http} / / / \mathrm{dx}$. doi.org/10.1016/j. yfrne.2007.04.001

68. Joëls, M. y Baram, T.Z. (2009) The neuro-symphony of stress. Nature Reviews in Neuroscience, 10, 459-466.

69. Joëls, M., Fernandez, G. y Roozendaal, B. (2011). Stress and emotional memory: a matter of timing. Trends in Cognitive Sciences, 15, 280-288. http://dx.doi.org/10.1016/j. tics.2011.04.004

70. Jonnakuty, C. y Gragnoli, C. (2008). What do we know about serotonin? Journal of Cellular Physioly, 217, 301306. http://dx.doi.org/10.1002/jep.21533

71. Kameda, S.R., Frussa-Filho, R., Carvalho, R.C., TakatsuColeman, A.L., Ricardo, V.P., Patti, C.L., et al. (2007). Dissociation of the effects of ethanol on memory, anxiety, and motor behavior in mice tested in the plus-maze discriminative avoidance task. Psychopharmacology, 192, 39-48. http://dx.doi.org/10.1007/s00213-006-0684-9

72. Karoutzou, G., Emrich, H.M. y Dietrich, D.E. (2008). The myelin-pathogenesis puzzle in schizophrenia: a literature review. Molecular Psychiatry, 13, 245-260. http://dx.doi.org/10.1038/sj.mp.4002096

73. Kempermann, G., Krebs, J. y Fabel, K. (2008). The contribution of failing adult hippocampal neurogenesis to psychiatric disorders. Current Opinion in Psychiatry, 21, 290295. http://dx.doi.org/10.1097/YCO.0b013e3282fad375

74. Kim, J.S., Kornhuber, H.H., Schmid-Burgk, W. y Holzmuller, B. (1980). Low cerebrospinal fluid glutamate in schizophrenic patients and a new hypothesis on schizophrenia. Neurosciences Letter, 20, 379-382. http://dx.doi. org/10.1016/0304-3940(80)90178-0

75. Kingsbury, M.A., Rehen, S.K., Contos, J.J., Higgins, C.M. y Chun, J. (2003). Nonproliferative effects of lysophosphatidic acid enhance cortical growth and folding. Nature Neuroscience, 6, 1292-1299. http://dx.doi.org/10.1038/nn1157

76. Koehl, M. y Abrous, D.N. (2011). A new chapter in the field of memory: adult hippocampal neurogenesis. European Journal of Neuroscience, 33, 1101-1114. http://dx.doi.org/10.1111/j.1460-9568.2011.07609.x

77. Lam, D.D., Przydzial, M.J., Ridley, S.H., Yeo, G.S., Rochford, J.J., O'Rahilly, S. y Heisler, L.K.
(1997). Serotonin 5-HT2C receptor agonist promotes hypophagia via downstream activation of melanocortin 4 receptors. Endocrinology, 149, 1323-1328. http://dx.doi.org/10.1210/en.2007-1321

78. e Strat, Y., Ramoz, N. y Gorwood, P. (2009). The Role of Genes Involved in Neuroplasticity and Neurogenesis in the Observation of a Gene-Environment Interaction (GxE) in Schizophrenia. Current Molecular Medicine, 9, 506-518. http://dx.doi.org/10.2174/156652409788167104

79. Leuner, B., Gould, E. y Shors, T.J. (2006). Is there a link between adult neurogenesis and learning? Hippocampus, 16, 216-224. http://dx.doi.org/10.1002/hipo.20153

80. Lin, M.E., Herr, D.R. y Chun, J. (2010). Lysophosphatidic acid (LPA) receptors: signaling properties and disease relevance. Prostaglandins and Other Lipid Mediators, 91,130138.http://dx.doi.org/10.1016/j.prostaglandins.2009.02.002

81. Lisman, J.E., Schulman, H. y Cline, H. (2002). The molecular basis of CaMKII function in synaptic and behavioural memory. Nature Reviews in Neuroscience, 3, 175-190. http://dx.doi.org/10.1038/nrn753

82. López, J.F., Liberzon, I., Vázquez, D.M., Young, E.A. y Watson, S.J. 1999. Serotonin 1A receptor messenger RNA regulation in the hippocampus after acute stress. Biological Psychiatry, 45, 934-937. http://dx.doi.org/10.1016/S00063223(98)00224-8

83. Lu, W.Y., Xiong, Z.G., Lei, S., Orser, B.A., Dudek, E., Browning, M.D. y MacDonald, J.F. (1999). G-proteincoupled receptors act via protein kinase $\mathrm{C}$ and $\mathrm{Src}$ to regulate NMDA receptors. Nature Neuroscience, 2, 331-338. http://dx.doi.org/10.1038/7243

84. Macklis, J.D. (2001). Neurobiology: new memories from new neurons. Nature, 410, 314-315. http://dx.doi. org $/ 10.1038 / 35066661$

85. Malleret, G., Hen, R., Guillou, J.L., Segu, L. y Buhot, M.C. (1999). 5-HT1B receptor knock-out mice exhibit increased exploratory activity and enhanced spatial memory performance in the Morris water maze. Journal of Neuroscience, 19, 6157-6168.

86. Marshall, F. y Titelbaum, P. 1974. Further analysis of sensory inattention flowing lateral hypothalamic damage in rats. Journal of Comparative and Physiological Psychology, 86, 375-395. http://dx.doi.org/10.1037/h0035941

87. Matas-Rico, E., García-Diaz, B., Llebrez-Zayas, P., LópezBarroso, D., Santín, L., Pedraza, C., Smith-Fernández, A., Fernández-Llebrez, P., Tellez, T., Redondo, M., Chun, J., De Fonseca, F.R. y Estivill-Torrús, G. (2008). Deletion of lysophosphatidic acid receptor LPA1 reduces neurogenesis in the mouse dentate gyrus. Molecular and Cellular Neuroscience, 39, 342-355. http://dx.doi.org/10.1016/j. mcn.2008.07.014

88. McEwen, B.S. (2000). Effects of adverse experiences for brain structure and function. Biological Psychiatry, 48, 721731. http://dx.doi.org/10.1016/S0006-3223(00)00964-1 
89. Mizuno, M., Yamada, K., He, J., Nakajima, A. y Nabeshima, T. (2003). Involvement of BDNF receptor TrkB in spatial memory formation. Learning and Memory, 10, 108-115. http://dx.doi.org/10.1101//m.56003

90. Moolenar, W.H., van Meeteren, L.A. y Giepmans, B.N.G. (2004). The ins and outs of lysophosphatidic acid signaling. BioEssays, 26, 870-881. http://dx.doi.org/10.1002/bies.20081

91. Mueller, N.K. y Beck, S.G. (2000). Corticosteroids alter the 5-HT(1A) receptor-mediated response in CA1 hippocampal pyramidal cells. Neuropsychopharmacology, 23, 419-427. http://dx.doi.org/10.1016/S0893-133X(00)00134-2

92. Murph, M.M., Nguyen, G.H., Radhakrishna, H. y Mills, G.B. (2008). Sharpening the edges of understanding the structure/function of the LPA1 receptor: expression in cancer and mechanisms of regulation. Biochimica et Biophysica Acta, 1781, 547-557. http://dx.doi.org/10.1016/j.bbalip.2008.04.007

93. Musazzi, L., Di Daniel, E., Maycox, P., Racagni, G. y Popoli, M. (2010). Abnormalities in $\alpha / \beta$-CaMKII and related mechanisms suggest synaptic dysfunction in hippocampus of LPA1 receptor knockout mice. International Journal of Neuropsychopharmacology, 14, 1-13.

94. Nishikawa, T., Tomori, Y., Yamashita, S. y Shimizu, S. (1989). Inhibition of $\mathrm{Na}+, \mathrm{K}+-\mathrm{ATPa} e$ activity by phospholipase A2 and several lysophospholipids: possible role of phospholipase A2 in noradrenaline release from cerebral cortical synaptosomes. Journal of Pharmacy and Pharmacology, 41, 450-458. http://dx.doi. org/10.1111/j.2042-7158.1989.tb06499.x

95. Noguchi, K., Herr, D., Mutoh, T. y Chun, J. (2009). Lysophosphatidic acid (LPA) and its receptors. Current Opinion in Pharmacology, 9, 15-23. http://dx.doi.org/10.1016/j. coph.2008.11.010

96. Noorbala, A.A., Akhondzadeh, S., Davari-Ashtiani, R. y Amini-Nooshabedi, H. (1999). Piracetam in the treatment of schizophrenia: implications for the glutamate hypothesis of schizophrenia. Journal of Clinical Pharmacy and Therapeutics, 24, 369-374. http://dx.doi.org/10.1046/j.13652710.1999.00238.x

97. Norman, R.M. y Malla, A.K. (1993). Stressful life events and schizophrenia. I: A review of the research. British Journal of Psychiatry, 162, 161-166. http://dx.doi.org/10.1192/ bjp.162.2.161

98. Norton, N., Williams, H.J. y Owen, M.J. (2006). An update on the genetics of schizophrenia. Current Opinion in Psychiatry, 19, 158-164. http://dx.doi.org/10.1097/01. yco.0000214341.52249.59

99. Oades, R.D. (1981). Type of memory or attention? Impairments after lesions of the hippocampus and limbic ventral tegmentum. Brain Research Bulletin, 7, 221-226. http:// dx.doi.org/10.1016/0361-9230(81)90086-1

100. Ohl, F., Roedel, A., Storch, C., Holsboer, F. y Landgraf,
R. (2002). Cognitive performance in rats differing in their inborn anxiety. Behavioral Neuroscience, 116, 464-471. http://dx.doi.org/10.1037/0735-7044.116.3.464

101. Ohnuma, T., Augood, S.J., Arai, H., McKenna, P.J. y Emson, P.C. (1999). Measurement of GABAergic parameters in the prefrontal cortex in schizophrenia: focus on GABA content, GABA(A) receptor alpha-1 subunit messenger RNA and human GABA transporter-1 (HGAT-1) messenger RNA expression. Neuroscience, 93, 441-448. http://dx.doi.org/10.1016/S0306-4522(99)00189-X

102. Parks, C.L., Robinson, P.S., Sibille, E., Shenk, T. y Toth, M. (1998). Increased anxiety of mice lacking the serotonin1A receptor. Proceedings of the National Academy of Sciences USA, 95, 10734-10739. http://dx.doi.org/10.1073/ pnas.95.18.10734

103. Perova, T., Wasserman, M.J., Li, P.P. y Warsh, J.J. (2008). Hyperactive intracellular calcium dynamics in B lymphoblasts from patients with bipolar I disorder. International Journal of Neuropsychopharmacoly, 11, 185-196. http:// dx.doi.org/10.1017/S1461145707007973

104. Perova, T., Kwan, M., Li, P.P. y Warsh, J.J. (2010). Differential modulation of intracellular $\mathrm{Ca} 2+$ responses in $\mathrm{B}$ lymphoblasts by mood stabilizers. International Journal of Neuropsychopharmacology, 13, 693-702. http://dx.doi. org/10.1017/S1461145709000261

105. Pilpel, Y. y Segal, M. (2006). The role of LPA1 in formation of synapses among cultured hippocampal neurons. Journal of Neurochemistry, 97, 1379-1392. http://dx.doi. org/10.1111/j.1471-4159.2006.03825.x

106. Pittenger, C. y Duman, R.S. (2008). Stress, depression, and neuroplasticity: a convergence of mechanisms. Neuropsychopharmacology, 33, 88-109. http://dx.doi.org/10.1038/ sj.npp. 1301574

107. Pyka, M., Busse, C., Seidenbecher, C., Gundelfinger, E.D. y Faissner, A. (2011). Astrocytes are crucial for survival and maturation of embryonic hippocampal neurons in a neuron-glia cell-insert coculture assay. Synapse, 65, 41-53. http://dx.doi.org/10.1002/syn.20816

108. Quincozes-Santos, A., Abib, R.T., Leite, M.C., Bobermin, D., Bambini-Junior, V., Gonçalves, C.A., Riesgo, R. y Gottfried, C. (2008). Effect of the atypical neuroleptic risperidone on morphology and S100B secretion in C6 astroglial lineage cells. Molecular and Cellular Biochemistry, 314, 59-63. http://dx.doi.org/10.1007/s11010-008-9765-x

109. Ramos, A. y Mormede, P. (1998). Stress and emotionality: A multidimensional and genetic approach. Neuroscience \& Biobehavioral Reviews, 22, 33-57. http://dx.doi. org/10.1016/S0149-7634(97)00001-8

110. Reif, A., Fritzen, S., Finger, M., Strobel, A., Lauer, M., Schmitt, A. y Lesch, K.P. (2006). Neural stem cell proliferation is decreased in schizophrenia, but not in depression. Molecular Psychiatry, 11, 514-522. http://dx.doi. org/10.1038/sj.mp.4001791 
111. Rivera, R. y Chun, J. (2008). Biological effects of lysophospholipids. Reviews of Physiology,Biochemistry \& Pharmacology, 160, 25-46. http://dx.doi.org/10.1007/112 0507

112. Roberts, C., Winter, P., Shilliam, C.S., Hughes, Z.A., Langmead, C., Maycox, P.R. y Dawson, L.A. (2005). Neurochemical changes in LPA1 receptor deficient mice--a putative model of schizophrenia. Neurochemical Research, 30, 371-377. http://dx.doi.org/10.1007/s11064-005-2611-6

113. Ross, R.G., Stevens, K.E., Proctor, W.R., Leonard, S., Kisley, M.A., Hunter, S.K., Freedman, R. y Adams, C.E. (2010). Research review: Cholinergic mechanisms, early brain development, and risk for schizophrenia. Journal of Child Psychology and Psychiatry, 51, 535-549. http:// dx.doi.org/10.1111/j.1469-7610.2009.02187.x

114. Santín, L.J., Bilbao, A., Pedraza, C., Matas-Rico, E., Lopez-Barroso, D., Castilla-Ortega, E., Sánchez-López, J., Riquelme, R., Varela-Nieto, I., de la Villa, P., Suardíaz, M., Chun, J., De Fonseca, F.R. y Estivill-Torrús, G. (2009). Behavioral phenotype of maLPA1-null mice: increased anxiety-like behavior and spatial memory deficits. Genes Brain \& Behavior, 8, 772-784. http://dx.doi.org/10.1111/ j.1601-183X.2009.00524.x

115. Savitz, J., Lucki, I. y Drevets, W.C. (2009). 5-HT(1A) receptor function in major depressive disorder. Progress in Neurobiology, 88, 17-31. http://dx.doi.org/10.1016/j.pneurobio.2009.01.009

116. Saxe, M.D., Malleret, G., Vronskaya, S., Mendez, I., Garcia, A.D., Sofroniew, M.V., et al. (2007). Paradoxical influence of hippocampal neurogenesis on working memory. Proceedings of the National Academy of Sciences USA, 104, 4642-4646. http://dx.doi.org/10.1073/ pnas. 0611718104

117. Schwabe, L., Joëls, M., Roozendaal, B., Wolf, O.T. y Oitzl, M.S. (2011). Stress effects on memory: An update and integration. Neuroscience \& Biobehavioral Reviews, (2011). http://dx.doi.org/10.1016/j.neubiorev.2011.07.002

118. Selemon, L.D. y Goldman-Rakic, P.S. (1999). The reduced neuropil hypothesis: a circuit based model of schizophrenia. Biological Psychiatry, 45, 17-25. http://dx.doi. org/10.1016/S0006-3223(98)00281-9

119. Shors, T.J. (2004). Memory traces of trace memories: neurogenesis, synaptogenesis and awareness. Trends in Neurosciences, 27, 250-256. http://dx.doi.org/10.1016/j. tins.2004.03.007

120. Shors, T.J., Miesegaes, G., Beylin, A., Zhao, M., Rydel, T. y Gould, E. (2001). Neurogenesis in the adult is involved in the formation of trace memories. Nature, 410, 372-376. http://dx.doi.org/10.1038/35066584

121. Tabuchi, S., Kume, K., Aihara, M. y Shimizu, T. (2000). Expression of lysophosphatidic acid receptor in rat astrocytes: mitogenic effect and expression of neurotrophic genes. Neurochemical Research, 25, 573-582. http://dx.doi. org/10.1023/A:1007542532395
122. Tamminga, C.A. y Holcomb, H.H. (2005). Phenotype of schizophrenia: a review and formulation. Molecular Psychiatry, 10, 27-39. http://dx.doi.org/10.1038/sj.mp.4001563

123. Tecott, L.H. (2007). Serotonin and the orchestration of energy balance. Cell Metabolism, 6, 352-361. http://dx.doi. org/10.1016/j.cmet.2007.09.012

124. Tigyi, G., Fischer, D.J., Sebok, A., Yang, C., Dyer, D.L. y Miledi, R. (1996). Lysophosphatidic acid-induced neurite retraction in PC12 cells: control by phosphoinositide-Ca2+ signaling and Rho. Journal of. Neurochemistry, 66, 537-548. http://dx.doi.org/10.1046/j.1471-4159.1996.66020537.x

125. Tkachev, D., Mimmack, M.L., Ryan, M.M., Wayland, M., Freeman, T., Jones, P.B., Starkey, M., Webster, M.J., Yolken, R.H. y Bahn, S. (2003). Oligodendrocyte dysfunction in schizophrenia and bipolar disorder. Lancet, 362, 798-804. http://dx.doi.org/10.1016/S0140-6736(03)14289-4

126. Tyler, W.J., Alonso, M., Bramham, C.R. y Pozzo-Miller, L.D. (2002). From acquisition to consolidation: On the role of brain-derived neurotrophic factor signaling in hippocampal-dependent learning. Learning and Memory, 9, 224-237. http://dx.doi.org/10.1101/1m.51202

127. Van den Buuse, M. (2010). Modeling the positive symptoms of schizophrenia in genetically modified mice: pharmacology and methodology aspects. Schizophrenia Bulletin, 36, 246-270. http://dx.doi.org/10.1093/schbul/sbp132

128. Van Haren, N.E., Hulshoff Pol, H.E., Schnack, H.G., Cahn, W., Brans, R., Carati, I., Rais, M. y Kahn, R.S. (2008). Progressive brain volume loss in schizophrenia over the course of the illness: evidence of maturational abnormalities in early adulthood. Biological Psychiatry, 63, 106-113. http://dx.doi.org/10.1016/j.biopsych.2007.01.004

129. Van Meeteren, L.A. y Moolenaar, W.H. (2007). Regulation and biological activities of the autotaxin-LPA axis. Progress in Lipid Research, 46, 145-160. http://dx.doi. org/10.1016/j.plipres.2007.02.001

130. Van Praag, H., Schinder, A.F., Christie, B.R., Toni, N., Palmer, T.D. y Gage, F.H. (2002). Functional neurogenesis in the adult hippocampus. Nature, 415, 1030-1034. http:// dx.doi.org/10.1038/4151030a

131. Warner-Schmidt, J.L. y Duman, R.S. (2006). Hippocampal neurogenesis: opposing effects of stress and antidepressant treatment. Hippocampus, 16, 239-249. http://dx.doi. org/10.1002/hipo.20156

132. Weiger, W.A. (1997). Serotonergic modulation of behaviour: a phylogenetic overview. Biological Reviews, 72, 61-95 http://dx.doi.org/10.1017/S0006323196004975

133. Weinberger, D.R. (1987). Implications of normal brain development for the pathogenesis of schizophrenia. Archives of General Psychiatry, 44, 660-669.

134. Whishaw, I.Q. (1995). Rats with fimbria-fornix lesions display a place response in a swimming pool: a dissociation between getting there and knowing where. Journal of Neuroscience, 15, 5779-5788. 
135. Whitford, T.J., Kubicki, M., Schneiderman, J.S., O’Donnell, L.J., King, R., Alvarado, J.L., Khan, U., Markant, D., Nestor, P.G., Niznikiewicz, M., McCarley, R.W., Westin, C.F. y Shenton, M.E. (2010). Corpus callosum abnormalities and their association with psychotic symptoms in patients with schizophrenia. Biological Psychiatry, 68, 70-77. http://dx.doi.org/10.1016/j.biopsych.2010.03.025

136. Wolff, A.L. y O'Driscoll, G.A. (1999). Motor deficits and schizophrenia: the evidence from neuroleptic-naive patients and populations at risk. Journal of Psychiatry \& Neuroscience, 24, 304-314.

137. Wright, I.C., Rabe-Hesketh, S., Woodruff, P.W., David, A.S., Murray, R.M. y Bullmore, E.T. (2000). Meta-analysis of regional brain volumes in schizophrenia. American Journal of Psychiatry, 157, 16-25.

138. Yoon, T., Okada, J., Jung, M.W. y Kim, J.J. (2008). Prefrontal cortex and hippocampus subserve different components of working memory in rats. Learning and Memory, 15, 97-105. http://dx.doi.org/10.1101/1m.850808
139. Zhang, X.F., Schaefer, A.W., Burnette, D.T., Schoonderwoert, V.T. y Forscher, P. (2003). Rhodependent contractile responses in the neuronal growth cone are independent of classical peripheral retrograde actin flow. Neuron, 40, 931-944. http://dx.doi.org/10.1016/S0896-6273(03)00754-2

Fecha de recepción: 29 de agosto de 2011 Fecha de aceptación: 15 de septiembre de 2011 